\section{Caring for Our Elders: Ha- waii's Chance to Make History}

\section{Clementina D Ceria-Ulep ${ }^{1 *}$ and Kevin Simowitz ${ }^{2}$}

${ }^{1}$ Faith Action for Community Equity (FACE) Long Term Care Task Force, Co-Chair \& Professor \& Chair, Department of Nursing at the University of Hawaii at Manoa School of Nursing \& Dental Hygiene, Department of Nursing, Honololu, HI, USA

${ }^{2}$ Political Director, Caring Across Generations, New York, NY, USA

In 2016, Hawaii's legislators had a chance to make history. Senator Roz Baker, supported by a number of other co-sponsors and allies, introduced legislation to create a new piece of care infrastructure for Hawaii which would have created a long term care benefits trust fund to provide access to a certain amount of resources each day, for 365 days, to assist in paying for in-home care.

\section{Why is this Necessary?}

Every eight seconds, someone in the country turns 65 years old. That's 10,000 aging adults per day, and 4 million in a year [1]. This has resulted to over 40 million unpaid caregivers of adults ages 65 and older in the United States [2,3]. These include caregivers, who are assisting their parents in handling their affairs and/or caring for them (44\%), caring for a friend or neighbor (18\%), grandparent (16\%), spouse/partner (7\%), other relative $(22 \%)$ and someone else $(6 \%)$. Note that the sum of caregivers are providing help to is greater than $100 \%$ since some caregivers are providing care to more than one person. [3].

Long-term care is especially an urgent issue in Hawaii due to its aging population profile. Between 2000 and 2010, while the 85+ population grew by roughly 30 percent nationally, it soared by 72 percent in Hawaii $[4,5]$. The rapid aging of Hawaii may be due to several factors, people living longer [6] and the longer life expectancy for some of the major ethnic groups such as the Chinese [7], Japanese [8-10]. As the older population expands in size, so too the demand for long-term services and supports [6]. Because the demographic makeup of our state is changing, we also need to change the way we provide care for older Hawaii residents.

Caring for our elders has been an issue that has been raised by members of Faith Action for Community Equity (FACE), an interfaith grassroots organization in Hawaii, since it came into being in 1996. FACE has been working on this issue for 20 years!

FACE members and others have shared their caregiving struggles including emotional and physical stress. Members of FACE

\footnotetext{
*Corresponding author: Clementina D Ceria-Ulep, Faith Action for Community Equity (FACE) Long Term Care Task Force, HI, Tel: +1 808-956-5225; Fax: +1 808-956-3257; E-mail: clem@hawaii.edu

Citation: Ceria-Ulep CD, Simowitz K (2016) Caring for Our Elders: Hawaii's Chance to Make History. J Gerontol Geriatr Med 2: 009.
}

Received: April 12, 2016; Accepted: June 02, 2016; Published: June 16, 2016 have changed their work schedules - working part-time or retiring early to be caregivers, putting themselves at risk for the future, they have been challenged with balancing work and family responsibilities. They have neighbors/friends whose parent(s) need adult day care services but do not have the money to pay for it. Others are selling their parents' home to pay for care. They have seen friends' family unity break from caregiving burnout. Their experiences with caregiving strain are consistent with other caregivers locally and nationally $[2,9,11,12]$. Family caregivers are the backbone of our care system and desperately need our investment and support. The legislation introduced would have provided such support.

\section{About the legislation}

If passed, Hawaii would have been the first state in the nation to create such a program - and through this would have been leading the nation in establishing public policy that so clearly matches our state's values of caring for our kupuna (elders). The legislation calls for a long-term care benefit of $\$ 70$ per day for 365 days and would establish a "care floor," ensuring that everyone would have access to basic resources to provide care at home. This fund was not meant to cover a stay in a long-term care facility like a nursing home or an assisted living home; what it would cover includes assistance with daily living, like hiring home care aides to help care for the elderly as well as equipment, like walkers and ramps so that they can stay at home safely and comfortably. To qualify for the full benefit, an individual would need to file income tax returns in Hawaii for ten years. The trigger for qualifying for care is someone needing assistance with at least two or more activities of daily living, such as bathing, dressing, eating, or walking.

\section{How would we pay for it?}

The fund would be created by increasing the General Excise Tax (GET) by $0.5 \%$. Because people who are visiting Hawaii pay GET on their purchases, about 35 percent of the amount of money paid into this fund will be paid by people who come to Hawaii to enjoy what the state has to offer.

This fund would be administered by a group of Trustees, whose job it will be to ensure the long-term health of this trust fund. Money in this fund can and will only be used to help provide long-term care; it is not part of the general revenue fund.

\section{Has anyone researched this?}

Yes! Extensive research has been conducted throughout the years, and this bill is rooted in the 2014 report by the Executive Office of Aging in Hawaii which recommended a publicly-funded program like the one this bill would create. In addition, studies done by National Alliance for Caregiving and AARP [2,11] and Browne et al, [9] document the need for support for caregivers who are dealing with long hours of caregiving, e.g., $>40$ hours per week, worsening health due to intensivity of providing care and assistance on navigating through the health care system including providers, community services, or government agencies. 


\section{How come it was not passed?}

Opposition came from the business community indicating that a $0.5 \%$ increase in the GET would hurt Hawaii's businesses and economy. However, using and input-output model, Liou and Nitz [13] looked at how a $0.5 \%$ surcharge on the GET will impact the state's Gross Domestic Product (GDP), earnings, state tax output, and jobs. To complement this analysis, the boost to the economy when the tax revenue is distributed as benefits for Long-Term Care Services and Supports was also estimated. Their analysis revealed that the $0.5 \%$ GET increase will have a significant, positive impact on Hawaii's economy including significant contributions to the GDP, earnings, state tax and job increase. Others said the tax increase is regressive. That is, it would weigh most heavily on low-to-moderate income families that the bill was supposed to help. Some politicians also said, "This is an election year, and anyone who would increase a tax might not get re-elected". That reaction from elected officials is a sad comment, for surely, it is during an election year when conversations should be about what is important to the people.

While there was decidedly little public opposition to the proposal leading up to the hearing in the Senate Ways and Means committee, the Chamber of Commerce of Hawaii offered testimony opposing the bill, as did other anti-tax organizations. One of the most unfortunate components of this testimony was that much of it was not rooted in fact, often conflating the proposed increase in GET for long-term care with another proposal in front of the legislature and suggesting that research, long-completed and well-documented, still remained to be done. In the coming legislative session, we hope to be able to work in good faith with organizations who voiced their opposition to the bill without our having the chance to have a conversation with them about the possible merits of the legislation.

We also hope that our friends at Hawaii AARP join the public campaign to support this legislation in the coming year. As the public awareness campaign, funded by the legislature through the Executive Office on Aging, is launched, we have every expectation that AARP will lend their expertise and voice in support of this essential piece of legislation.

\section{What we learned}

There is general consensus in this country that a long term care program is needed, and that it will require at least some amount of public investment. However, even our friendly legislators do not all have the political will right now to raise taxes, leaving us without unified support for a funding source for that program. In both the Senate and the House, our bill died in the money committees. At its core, the fight is about the role of government and raising money-and in Hawaii and in all states where we try to move forward with social insurance legislation, we have to be willing to address the issue of revenue head-on.

Because of this, the ground game we build is so important. We will not win something so bold without a robust organizing campaign, where we have multigenerational voices in diverse communities, in faith institutions, universities, and beyond making demand on their legislators. The issue is seen as so private-we have to bring it out of our homes and make it a public issue.

We also learned that basic public education is badly needed and can be a useful starting place for organizing. People continue to think that Medicare will cover their long term care costs, or they have simply not thought about their plan for care. This year, there will be a public education effort that the Executive Office on Aging in Hawaii has contracted to help people understand their options, or rather, their lack of options, in the current system of long-term care. We are hopeful this will complement the organizing work FACE continues to lead across the state.

We also gained some insight into messaging; specifically, we experimented with focusing on the support this legislation would have on family caregivers and therefore on the seniors they are caring for who want to remain at home. This was effective in some ways. However, we did not offer strong enough messaging in two areas. One, we need to articulate the economic benefit of a new public program: infusing resources into the care system will create care jobs, something voters and elected officials care a lot about. Two, we also need to more strongly challenge the concern over raising taxes, which was the core argument made by the opposition. We cannot simply avoid the issue and hope that "care for our elders" will matter more to decision-makers than the program's cost. We have to squarely argue why paying for this program is an investment that will save the state money in the long term.

Lastly, we saw the power of stories. The issue is personal and private, the more we talked about caregiving in communities across Hawaii, the more we found out just how many people are touched by the issue. This may not be surprising, but a good reminder that the need for care is universal.

\section{On the horizon}

FACE will be back at the Hawaii State Legislature in 2017, working with Senator Roz Baker to address the concerns raised by those who opposed the bill. FACE will continue to work with Caring Across Generations to make sure that the bill passes next year!

Across the country, more and more elected officials are beginning to approach the changing demographics of their state as a public policy issue that demands both attention and action. The work done in Hawaii to advance a public social insurance program is groundbreaking, and serves as an early model on which other states will build to create programs that help ensure that everyone has affordable access to home and community-based services as they age.

\section{References}

1. Pew Research Center (2010) Baby boomers retire. Pew Research Center, Washington DC, USA.

2. National Alliance for Caregiving, AARP Public Policy Institute (2015) Caregiving in the US 2015. Research Report, National Alliance for Caregiving, Bethesda, MD, USA.

3. Stepler R (2015) 5 facts about family caregivers. Pew Research Center, Washington DC, USA.

4. US Census Burearu ( 2010) The older population: 2010. 2010 Census briefs, US Department of Commerce Economics and Statistics Administration, US Census Burearu, Maryland,USA.

5. Riker M (2015) Hawaii's senior population growing 4 times faster than state as a whole. Civil Beat, Honolulu, Hawaii, USA.

6. Hawaii Executive Office on Aging (2014) The Feasibility of a Long-Term Services and Supports Social Insurance Program for Hawaii. A Report to the Hawaii State Legislature, Hawaii LTSS Feasibility Study V.8.2.Docx, Executive Office on Aging, Department of Health, University of Hawaii Research Corporation, Hawaii, USA.

7. Park CB, Braun KL, Horiuchi BY, Tottori C, Onaka AT (2009) Longevity disparities in multiethnic Hawaii: an analysis of 2000 life tables. Public Health Rep 124: 579-584. 
8. Bell CL, Chen R, Masaki K, Yee P, He Q, et al. (2014) Late-life factors associated with healthy aging in older men. J Am Geriatr Soc 62: 880-888.

9. Browne CV, Mokuau N, Ka'opua LS, Kim BJ, Higuch P, et al. (2014) Listening to the voices of native Hawaiian elders and 'ohana caregivers: discussions on aging, health, and care preferences. J Cross Cult Gerontol 29: 131-151.

10. He Q, Morris BJ, Grove JS, Petrovitch H, RossW, et al. (2014) Shorter men live longer: association of height with longevity and FOXO3 genotype in American men of Japanese ancestry. PLoS One 9: 94385.
11. National Alliance for Caregiving, AARP (2004) Caregiving in the US, National Alliance for Caregiving and AARP, USA

12. Korn L, Logsdon RG, Polissar NL, Gomez-Beloz A, Waters T, et al. (2009) A Randomized Trial of a CAM Therapy for Stress Reduction in American Indian and Alaskan Native Family Caregivers. Gerontologist 49: 368-377.

13. Liou W, Nitz LH (2015) Long-term services \& supports feasibility policy note - Assessing the costs and benefits of a long-term care insurance program in Hawaii. Department of Political Science, College of Social Sciences, University of Hawaii, Manoa, Hawaii, USA. 